UDC 340.13

LBC 67.021

\title{
THE PROBLEMS OF ENSURING LEGAL JUSTICE IN INTERBRANCH DIFFERENTIATION OF LEGAL LIABILITY ${ }^{1}$
}

\author{
Aleksey P. Rozhnov \\ Volgograd State University, Volgograd, Russian Federation
}

\begin{abstract}
The article reveals the concept of the principle of justice and its relationship with the differentiation of legal liability. On the example of regulation of this principle in the criminal legislation of the Russian Federation it is emphasized that its addressees are not only bodies of application of law but also the legislator who has to prohibit only socially dangerous acts under the threat of punishment and establish proportionate sanctions for their committing.

The concept of legal justice is revealed through its equalizing and distributing aspects. The latter aspect which is the need to reward each individual in proportion to their positive and negative contributions to public life has a direct bearing on the establishment of liability. Therefore the differentiation of liability understood as its legislative "stratification" should take into account the properties of the committed offense at the legislative level and, to put it through a measure, the type and size of the sanction, be adequate to it. To achieve justice in the process of inter-sectoral differentiation of liability it is proposed to comply with a number of requirements: any legal liability should be established only for a truly socially dangerous act; the next step in establishing fair liability should initially be the correct definition of the type of its sanctions - punitive or remedial and the correct definition of the sphere of law from which the breach of the rules determines the typical nature of liability (public or private). Within the actual inter-sectoral differentiation of the liability it must also be properly distinguished between standing close to each other offenses from different areas of public law using already proven tools of differentiation (the extent of material effects, the mechanism of administrative prejudice), to maintain continuity of legal liability, clearly state the differentiating characteristics of related offences in various industrial branches, to prevent criminalization (save criminalization) non-criminal acts.
\end{abstract}

Key words: justice, legal justice, danger to the public, interbranch differentiation of liability, offense, wrongdoing, crime, legal liability.

УДК 340.13

ББК 67.021

\section{ПРОБЛЕМЫ ОБЕСПЕЧЕНИЯ ЮРИДИЧЕСКОЙ СПРАВЕДЛИВОСТИ ПРИ МЕЖОТРАСЛЕВОЙ ДИФФЕРЕНЦИАЦИИ ЮРИДИЧЕСКОЙ ОТВЕТСТВЕННОСТИ ${ }^{1}$}

\author{
Алексей Петрович Рожнов \\ Волгоградский государственный университет, г. Волгоград, Российская Федерация
}

\begin{abstract}
Аннотация. В статье раскрывается понятие принципа справедливости и его связь с дифференциацией юридической ответственности. На примере урегулирования данного принципа в уголовном законодатель- стве РФ подчеркивается, что его адресатом являются не только органы применения права, но и сам законодатель, который должен запрещать под угрозой наказания только общественно опасные деяния и устанавливать соразмерные санкции за их совершение.

Понятие юридической справедливости раскрывается через ее уравнивающий и распределяющий аспекты. Последний аспект, заключающийся в необходимости воздаяния каждому индивиду пропорционально его позитивному и негативному вкладу в общественную жизнь, имеет непосредственное отношение к воп○. росам установления ответственности. Следовательно, дифференциация ответственности, понимаемая как ее () законодательное «расслоение», должна учитывать на законодательном уровне свойства совершенного пра-
\end{abstract}


вонарушения и, выражаясь через меру, вид и размер санкции, быть адекватной ему. Для достижения справедливости в процессе межотраслевой дифференциации ответственности предлагается соблюдение ряда требований: любая юридическая ответственность должна устанавливаться лишь за реально общественно опасное деяние; следующим этапом установления справедливой ответственности должно быть изначально правильное определение типа ее санкций - карательные или правовосстановительные, а также правильное определение той сферы права, нарушение норм из которой определяет типовую природу ответственности (публичная или частная). При собственно межотраслевой дифференциации ответственности необходимо также правильно разграничивать близко стоящие друг к другу правонарушения из разных отраслей публичного права, используя уже проверенные средства дифференциации (размер материальных последствий, механизм административной преюдиции), сохранять преемственность юридической ответственности, четко указывать разграничительные признаки смежных правонарушений различной отраслевой принадлежности, не допускать криминализации (сохранения криминализации) непреступных деяний.

Ключевые слова: справедливость, юридическая справедливость, общественная опасность, межотраслевая дифференциация ответственности, правонарушение, проступок, преступление, юридическая ответственность.

Большинством правоведов, представляющих общую теорию российского права, признается, что объективное право представляет собой «систему норм, выраженных в законах, иных признаваемых государством источниках и являющихся общеобязательным, нормативно-государственным критерием правомерно-дозволенного (а также запрещенного и предписанного) поведения» [3, с. 123]. Однако рассмотрение права только как системы норм, представляющих собой обязательные правила поведения и ничего более, приводит к игнорированию других многочисленных предписаний, получивших свое формальное выражение в юридических источниках и также участвующих в регулировании социальных связей, «несет в себе упрощенный образ правовой действительности, ...ведет к недооценке реального многообразия правовой материи» $[6$, с. 213].

Таким образом, составляющие содержание права нормы неоднородны и существенно различаются между собой по своей функциональной роли в механизме правового регулирования, оставаясь, тем не менее, единым родовым образованием в плане своей устремленности к общей цели и назначению права - быть универсальным регулятором поведения людей, охраняемым принудительной силой государства.

В зависимости от функционального назначения правового предписания, составляющего ткань права, в зависимости от механизма его воздействия на социальные связи, наряду с собственно правовыми нормами, принято выделять так называемые «исходные нормы» (М.И. Байтин) [5, с. 213], образующие нормативно-вспомогательную часть права (С.С. Алексеев) [2, с. 71], которые регулируют социальные связи опосредованно, через другие нормы [20, с. 15]. «Сердцевину» нормативно-вспомогательной части составляют принципы права, которые представляют собой базовые фундаментальные начала всей или части системы права (нескольких отраслей, одной отрасли, института), получающие большую или меньшую степень своей формальной объективации, определяющие содержание других норм, задающие определенную направленность режима правового регулирования [5, c. $156 ; 10$, c. 34$]$.

Думается, не будет ошибкой определить правовые принципы и как своеобразную «визитную карточку», краткую «аннотацию» определенной национальной системы права, его конкретных отраслей и институтов. Именно принципы права характеризуют демократичность права отдельно взятого государства, его ориентированность и устремленность на защиту классовых либо общенародных интересов, систему разделяемых и защищаемых государством ценностей, приоритеты государственной поддержки, режим функционирования государственных органов и т. п. Как остроумно было замечено К.А. Гельвецием, «знание некоторых принципов легко возмещает незнание некоторых фактов» [11, с. 329].

Как представляется, нет никаких оснований отказываться от деления всех принципов, так или иначе проявляющих себя в сфере права, на общеправовые, межотраслевые и отраслевые. К общим (общеправовым) принци- 
пам относятся те принципы, которые свойственны для всех отраслей данной правовой системы государства [23, с. 155], это основные идеи системы права в целом, отражающие «ведущие начала процесса формирования, развития и функционирования для всех норм, институтов и отраслей права» [10, с. 36-37].

Традиционно и практически единодушно в число общеправовых принципов включается принцип справедливости. Более того, социологический подход к познанию сущности права фактически отождествляет право и справедливость, делая право отражением реально сложившегося порядка общественных отношений и, таким образом, воплотившейся в нем (порядке) справедливости [10, с. 33]. «Право, - пишет Р.3. Лившиц, - есть нормативно закрепленная и реализованная справедливость» [18, с. 69]. По мнению В.С. Нерсесянца, «только право и справедливо», поскольку справедливость «воплощает собой... общезначимую правильность, а это в своем рационализированном виде означает всеобщую правомерность, то есть существо и начало права, смысл правового принципа всеобщего равенства и свободы» [19, с. 28].

Однако удивительно, что при такой значимости категории справедливости, приобретающей фундаментальное значение для права и правовой системы в целом, как своего рода мерила различения истинно правового и неправового (пусть и формально-законного), данный принцип нашел свое легальное закрепление лишь только единожды - в ст. 6 гл. 1 действующего УК РФ. Примечательно, что и наибольшую теоретическую разработанность данный принцип также нашел в трудах по уголовному праву.

Судя по содержанию ст. 6 УК РФ, принцип справедливости в сфере уголовного правосудия проявляет себя в двух аспектах: через требование о соответствии наказания и иных мер уголовно-правового характера характеру и степени общественной опасности преступления, обстоятельствам его совершения и личности виновного (ч. 1 ст. 6), а также в виде запрета нести уголовную ответственность дважды за одно и то же преступление (ч. 2 ст. 6). Таким образом, Кодекс увязывает действие принципа справедливости исключительно с властной правореализацией, не ос- тавляя места для его проявления в сфере законотворчества. Однако такой взгляд, проистекающий из буквального толкования уголовного закона, конечно, упрощает правовую реальность, ибо уголовный закон, во-первых, выражает далеко не все принципы отрасли, а во-вторых, содержание даже нашедших свою формализацию принципов порой гораздо шире их текстуального изложения. Поэтому, как правильно замечает В.Ф. Щепельков, критикуя нормативное содержание принципа справедливости в ст. 6 УК РФ, «наказание и иные меры уголовно-правового характера могут быть справедливыми только в том случае, если требование справедливости выдержано уже при установлении уголовно-правовых норм» [22, с. 99]. Отсюда вполне резонно замечено, что «принцип справедливости, коль речь идет об уголовном праве, проявляется и в законотворческом аспекте в том числе. Причем в последнем он воплощается в двух ракурсах: при формировании круга общественно опасных деяний и при определении санкции» [4, с. 14].

Правовая справедливость, замечает Н.Н. Вопленко, выглядит «как нравственноправовой идеал, к которому должно стремиться право во всех основных формах своего бытия: правосознании, законодательстве и юридической практике» [7, с. 7]. Для России это приобретает особое значение, поскольку, как обоснованно замечают современные правоведы, «русская правоведческая традиция, возрождаемая в условиях реформирования современной российской государственности, возникла как форма поиска религиозных и нравственных оснований права, ориентированного на национально-государственный идеал, включающий и нормы справедливости, и субъективное право, обеспечивающие единство прав и обязанностей» [21, с. 119].

Как отмечается в трудах по теории права, юридическую справедливость можно определить как «идею, принцип и соответствующий режим жизнедеятельности... посредством уравнивания положения субъектов в системе общественных отношений и воздаяния им пропорционально их позитивному и негативному вкладу в социальную жизнь» [9, c. 10]. Тем самым, принцип юридической справедливости предстает как диалектическое 
единство двух полюсов - формального равенства и фактического неравенства субъектов, уравнивающего и распределяющего (воздающего) аспектов данного феномена. Уравнивающий аспект справедливости заключается в правовом воплощении идеи равенства: через равноправие субъектов правовых отношений, предоставление им равных возможностей и равных гарантий защиты законом и т. п. Воздающий аспект юридической справедливости проявляется в предоставлении каких-либо благ пропорционально позитивному вкладу в общественную жизнь в процессе правомерного поведения (регулятивная справедливость), либо же в адекватном воздаянии за негативный поступок человека, соразмерно вредности такового (карательная справедливость) [8, c. 80-81]. Как видим, единственным адресатом карательной справедливости является юридическая ответственность, определяемая как «правоотношение, представляющее собой вид и меру наказания, установленные государством за нарушение норм права» [12, с. 280].

Юридическая ответственность и правонарушение - парные и взаимосвязанные категории, причем правонарушение выступает юридическим фактом, основанием, причиной возникновения правоотношения юридической ответственности. Наиболее четко это подчеркивается в базовых положениях уголовного закона, в частности, в его ст. 8, провозглашающей, что «основанием уголовной ответственности является совершение деяния, содержащего все признаки состава преступления, предусмотренного настоящим Кодексом».

Совершенно очевидно, что все правонарушения различаются между собой. Причем это различение происходит на самых разных «пластах», уровнях и «срезах» права: на уровне деления права на суперотрасли (правонарушение публичное и правонарушение в сфере частного права), на уровне отрасли (преступления, административные проступки, налоговые правонарушения и пр.), на уровне института и пр. Отсюда и юридическая ответственность не может быть «монолитной», ибо она не существует «вообще», «в принципе». Будучи «применением к лицу, совершившему правонарушение, мер государственного принуждения, предусмотренных санкцией нарушенной нормы, в установленном для этого процессуальном порядке» [16, с. 592], ответственность является реакцией на поступок человека. Данные же поступки не могут быть одинаковыми, а потому не может быть одинаковой и государственная реакция за них. Именно «разность» человеческих поступков, посягающих на сложившийся порядок, и вызывает «к жизни» такое явление, как дифференциация юридической ответственности. Дифференциация ответственности, по мнению Л.Л. Кругликова, представляет собой «осуществляемое законодателем разделение последней, дозировку с учетом определенного рода обстоятельств, целью которой является создание для правоприменителя желаемого режима при определении меры (вида и размера) ответственности за совершенное правонарушение» $[14$, с. 62$]$. Согласимся с цитированным определением «в целом», но все же заметим, что желаемый режим «определения меры (вида и размера) ответственности» не может быть целью дифференциации.

В трудах отечественных криминалистов обосновано отнесение дифференциации уголовной ответственности к числу принципов уголовного права $[13$, с. $177 ; 15$, с. $75 ; 17$, с. 87$]$. Не претендуя на качество принципа всего права, дифференциация юридической ответственности все же должна быть рассмотрена как составная часть принципа справедливости, поскольку именно справедливость в ее карательно-воздающем аспекте требует «расслаивать» на законодательном уровне юридическую ответственность пропорционально тяжести проступка, или (в терминологии Н.Н. Вопленко) пропорционально негативному вкладу индивида в общественную жизнь. Таким образом, целью процесса дифференциации, являющейся в системе права составной частью принципа справедливости, является исключительно цель конструирования в законе наиболее справедливых мер (видов, размеров) ответственности за те или иные правонарушения.

Самым первым уровнем дифференциации является «разнесение» ответственности по отраслям, ибо деление права на отрасли является естественным, внутренне присущим свойством права, следствием своего рода «самоорганизации» права исходя из характера, природы и содержания сложившихся в обществе отношений, нуждающихся в правовом 
«обслуживании». Отсюда принципиальным является разработка критериев обеспечения принципа справедливости при осуществлении межотраслевой дифференциации юридической ответственности, поскольку изначально неверное определение вида (формы) такой ответственности влечет за собой и иные сущностные законодательные и правоприменительные ошибки, сводящие к нулю ее потенциальный полезный эффект.

Думается, первым требованием, выступающим необходимой предпосылкой воплощения справедливости на уровне межотраслевой дифференциации ответственности, является ее (ответственности) установление за реально общественно опасное деяние. Наличие у всех без исключения правонарушений свойства общественной опасности не является общепризнанным [16, с. 606]. Отчасти этому способствует и сам закон. Так, явно неудачной, например, является формулировка ч. 2 ст. 14 УК РФ, позволяющая признавать малозначительным деяние, формально предусмотренное Кодексом как запрещенное, но «не представляющее общественной опасности». При буквальном ее прочтении может сложиться впечатление, что малозначительным будет только деяние, вообще не обладающее свойством общественной опасности. Не вдаваясь глубоко в суть вопроса, заметим лишь, что судебная практика относит к малозначительным и те деяния, которые по уровню своей опасности не могут быть признаны преступлениями, но при этом могут и должны квалифицироваться в качестве дисциплинарных, административных и иных проступков (деликтов). Это вполне закономерно. Следовательно, в ч. 2 ст. 14 УК РФ имеется в виду не отсутствие общественной опасности, а отсутствие лишь такой ее меры, которая не позволяет признать формально запрещенное УК деяние преступлением.

Допущение отсутствия общественной опасности в проступках (не-преступлениях) размывает границы понятия правонарушения, игнорирует единую социальную природу правонарушения и преступления, искусственно делает преступление особым правовым явлением, выводя его за рамки правонарушающего поведения, допускает произвольное применение санкций норм публичных отраслей пра- ва, фактически означает возможность произвольного установления иной (не-уголовной) ответственности в отсутствие действительной вредоносности того или иного поведения.

Вторым условием правильной (а значит, и справедливой) межотраслевой дифференциации юридической ответственности является изначально верное родовое «разнесение» конкретных мер ответственности по группам правовосстановительных или же карательных (штрафных) санкций. Для определения такой природы ответственности необходим правильный учет нарушенного регулятивного отношения, влияние допущенного нарушения на правопорядок, на стабильность социальных связей.

Как указывает О.Э. Лейст, правовосстановительные санкции направлены на устранение причиненного вреда либо угрозы его причинения, что достигается понуждением к исполнению обязанности в натуре, прекращением действий, создающих опасность для окружающих (устранение противоправных состояний), восстановлением нарушенных прав и пр. $[16$, с. 602]. Допущенное нарушение, требующее применения подобных санкций (обычно в сфере частного права), не создает существенной угрозы для правопорядка, поскольку имеет своим объектом, «сферой действия» «отношения, складывающиеся на базе имущественной обособленности их участников» $[1$, с. 476]. В свою очередь, в систему признаков правонарушения, переводящих его в ранг преступного, уже встраивается и личность правонарушителя, его мотивы, цели, вина, которые в совокупности с объективными признаками поведения существенно повышают уровень его общественной опасности, влекут более серьезные последствия для правопорядка и поэтому требуют применения уже карательных санкций, в том числе и для достижения общей превенции в целях искоренения прецедентности совершенного проступка.

Карательная (штрафная) ответственность наступает за дисциплинарные, налоговые, административные правонарушения и преступления. Удел этой ответственности публичный сегмент жизни государства и общества. Сфера действия правовосстановительной ответственности - отношения, складывающиеся в сфере частного права, основанные на свободе, определенной обособлен- 
ности, формальном равенстве и автономии воли своих участников. Изначально неверное определение типа ответственности - как правило, карательной вместо правовосстановительной (примером чему является советский этап развития России) - приводит к огосударствлению, тоталитаризму, стагнации экономики, уводит ее в тень, влечет криминализацию общества и т. д.

Следующим условием, являющимся предпосылкой установления справедливой ответственности на этапе ее межотраслевой дифференциации, является правильное типовое определение природы правонарушения как частного или публичного, что объективно предопределено делением всей системы права на две суперотрасли, или зоны права - публичное и частное.

На уровне «разнесения» ответственности по отраслям системы права обычно не возникает трудностей при измерении общественной опасности для отграничения отраслевых проступков из разных сегментов правовой действительности - например, гражданского правонарушения от административного проступка либо преступления. Сложности возникают как раз при определении видовой природы правонарушения и, как следствие, при выборе отраслевых методов воздействия на него. Наиболее остро данная проблема возникает в отношении правонарушений, находящихся как бы «на стыке» двух отраслей одной типовой (чаще всего, публичной) принадлежности: например, уголовного и административного права. В последние годы отечественный законодатель для разведения такого рода «стыковых» правонарушений (как правило, преступлений небольшой тяжести и административных правонарушений) активно пользуется следующими дифференцирующими средствами: установлением четкого размера последствий в материальных составах, выступающих своего рода буфером между административным деликтом и преступлением, криминообразующим признаком последнего (см., например: ч. 1 ст. 165 УК РФ и ст. 7.27.1 КоАП РФ); механизмом административной преюдиции, когда накопление общественной опасности за систему административных правонарушений переводит последнее в разряд преступления (см., например: ст. 157 УК РФ и ст. 5.35.1
КоАП РФ). Однако все же проводимую дифференциацию достаточной признать нельзя. Как указывается многими учеными, при проведении межотраслевой дифференциации, особенно касающейся вопросов разграничения уголовной и административной ответственности, «должна обеспечиваться преемственность в видах юридической ответственности» $[14$, с. 52]. Иначе говоря, там, где законодатель в качестве криминообразующего признака формализует размер материальных последствий преступления, логичнее было бы установление административной ответственности за такое же деяние, последствия от которого меньше размера, необходимого для наступления уголовной ответственности.

Помимо этого, при конструировании смежных деликтов различной отраслевой принадлежности (например, преступления и административного правонарушения) должны четко указываться в законе их разграничительные признаки. Для случаев отсутствия таковых должно быть установлено нормативно правило, являющееся воплощением принципа справедливости, согласно которому в подобных случаях подлежит применению норма об ответственности, содержащая наиболее лояльную с точки зрения и меры, и вида, и размера, и отраслевой принадлежности ответственности санкцию.

Недопустимым при проведении межотраслевой дифференциации видится установление либо сохранение уголовной ответственности за те деяния, которые или изначально не характеризовались свойственной преступлению общественной опасностью, или же утратили характерный именно для преступления размер таковой в силу смены исторического этапа в жизни страны и общества. Так, сыгравшая в период построения рыночной экономики свою положительную роль ст. 145.1 УК РФ, установившая уголовную ответственность за невыплату заработной платы, пенсий, стипендий, пособий и иных выплат, выглядит теперь явным анахронизмом. Думается, очевидным нарушением принципа справедливости является установление уголовной ответственности за те деяния, которые не содержат необходимого материального признака преступления в количественном либо в качественном его выражении. 


\section{ПРИМЕЧАНИЕ}

${ }^{1}$ Исследование выполнено при финансовой поддержке Российского фонда фундаментальных исследований, проект № 17-03-00720.

\section{СПИСОК ЛИТЕРАТУРЫ}

1. Алексеев, С. С. О составе гражданского правонарушения / С. С. Алексеев // Алексеев, С. С. Собрание сочинений. В 10 т. Т. 1 : Гражданское право: Сочинения 1958-1970 годов. - М. : Статут, 2010. $495 \mathrm{c}$.

2. Алексеев, С. С. Общая теория права : в 2 т. / С. С. Алексеев. - М. : Юрид. лит., 1982. - Т. 2. -360 с.

3. Алексеев, С. С. Теория права / С. С. Алексеев. - М. : БЕК, 1993. -223 с.

4. Арендаренко, А. В. Общеправовой принцип социальной справедливости и его реализация в современном уголовном праве России (теоретико-правовые аспекты) : автореф. дис. ... д-ра юрид. наук : 12.00 .01 / Арендаренко Алла Владимировна. М., 2009. -46 c.

5. Байтин, М. И. Вопросы общей теории государства и права / М. И. Байтин. - Саратов : Изд-во Сарат. гос. акад. права, 2006. - 400 с.

6. Вопленко, Н. Н. Очерки общей теории права / Н. Н. Вопленко. - Волгоград : Изд-во ВолГУ, 2009. $-898 \mathrm{c}$.

7. Вопленко, Н. Н. Понятие и виды юридической справедливости / Н. Н. Вопленко // Вестник Волгоградского государственного университета. Серия 5, Юриспруденция. -2011. - № 2 (15). - С. 7-17.

8. Вопленко, Н. Н. Понятие и виды юридической справедливости / Н. Н. Вопленко // Юридическая справедливость: проблемы теории и практики / под ред. И. В. Ростовщикова, В. А. Рудковского, Ю. А. Гавриловой ; авт. коллектив: В. М. Абдрашитов [и др.]. Волгоград : Изд-во ВолГУ, 2017. -С. 65-83.

9. Вопленко, Н. Н. Свобода и справедливость: закономерности их взаимодействия / Н. Н. Вопленко // Вестник Волгоградского государственного университета. Серия 5, Юриспруденция. - 2012. № 1 (16). - С. 7-12.

10. Вопленко, Н. Н. Сущность, принципы и функции права / Н. Н. Вопленко. - Волгоград : Изд-во ВолГУ, 1998. - $56 \mathrm{c}$.

11. Гельвеций, К. А. Об уме / К. А. Гельвеций // Гельвеций. Сочинения : в 2 т. / сост. и общ. ред. Х. Н. Момджяна.-М. : Мысль, 1973.- Т. I.-C. 326-481.

12. Иванников, И. А. Проблемы государства и права России начала XX века / И. А. Иванников. Ростов н/Д : Изд-во Рост. ун-та, 2003. - 352 с.

13. Костарева, Т. А. Квалифицирующие обстоятельства в уголовном праве (понятие, законода- тельная регламентация, влияние на дифференциацию ответственности) / Т. А. Костарева. - Ярославль : Изд-во Яросл. гос. ун-та, 1993. - 234 с.

14. Кругликов, Л. Л. Дифференциация ответственности в уголовном праве / Л. Л. Кругликов, А. В. Васильевский. - СПб. : Изд-во «Юридический центр Пресс», 2002. - 300 с.

15. Кругликов, Л. Л. Унификация в уголовном праве / Л. Л. Кругликов, Л. Е. Смирнова. - СПб. : Изд-во Р. Асланова «Юридический центр Пресс», 2008. -312 c.

16. Лейст, О. Э. Юридическая ответственность / О. Э. Лейст // Общая теория государства и права. Академический курс : в 2 т. Т. 2. Теория права / под ред. М. Н. Марченко. - М. : Зерцало, 1998. С. 592-621.

17. Лесниевски-Костарева, Т. А. Дифференциация уголовной ответственности. Теория и законодательная практика / Т. А. Лесниевски-Костарева. 2-е изд., перераб. и доп. - М. : НОРМА, 2000. - 400 с.

18. Лившиц, Р. 3. Теория права / Р. 3. Лившиц. М. : Бек, 1994. - 224 c.

19. Нерсесянц, В. С. Философия права / В. С. Нерсесянц. - М. : ИНФРА-М : НОРМА, 1997. - 652 с.

20. Филимонов, В. Д. Норма уголовного права / В. Д. Филимонов. - СПб. : Изд-во Р. Асланова «Юридический центр Пресс», 2004. - 281 с.

21. Цыбулевская, О. И. Власть и реформы в России: нравственно-правовой аспект / О. И. Цыбулевская, Т. В. Милушева ; под ред. С. Ю. Наумова. Саратов : Поволжская академия государственной службы им. П.А. Столыпина, 2003. - 200 с.

22. Щепельков, В. Ф. Уголовный закон: преодоление противоречий и неполноты / В. Ф. Щепельков. - М. : Юрлитинформ, 2003. - 416 с.

23. Явич, Л. С. Общая теория права / Л. С. Явич. Л. : Изд-во ЛГУ, 1976. -285 с.

\section{REFERENCES}

1. Alekseev S.S. O sostave grazhdanskogo pravonarusheniya [On the Structure of Tort]. Sobranie sochineniy. V 10 t. T. 1 [Collected Works. In 10 vols. Vol. 1]. Moscow, Statut Publ., 2010. 495 p.

2. Alekseev S.S. Obshchaya teoriya prava: $V 2 t$. T. 2 [The General TheoryofLaw. In 2 vols. Vol. 2]. Moscow, Yurid. lit. Publ., 1982.360 p.

3. Alekseev S.S. Teoriya prava [Theory of Law]. Moscow, BEK Publ., 1993. 223 p.

4. Arendarenko A.V. Obshchepravovoy printsip sotsialnoy spravedlivosti $i$ ego realizatsiya $v$ sovremennom ugolovnom prave Rossii (teoretikopravovye aspekty): avtoref. dis. ... d-ra yurid. nauk [General Legal Principle of Social Justice and Its Implementation in Contemporary Criminal Law of 
Russia (Theoretical and Practical Aspects). Dr. jurid. sci. abs. diss.]. Moscow, 2009. 46 p.

5. Baytin M.I. Voprosy obshchey teorii gosudarstva i prava [Problems of General Theory of State and Law]. Saratov, Izd-vo Sarat. gos. akad. prava, 2006. 400 p.

6. Voplenko N.N. Ocherki obshchey teorii prava [Outline of General Theory of Law]. Volgograd, Izd-vo VolGU, 2009. 898 p.

7. Voplenko N.N. Ponyatie i vidy yuridicheskoy spravedlivosti [Notion and Types of Legal Justice]. Vestnik Volgogradskogo gosudarstvennogo universiteta. Seriya 5, Yurisprudentsiya [Science Journal of Volgograd State University. Jurisprudence], 2011, no. 2 (15), pp. 7-17.

8. Voplenko N.N. Ponyatie i vidy yuridicheskoy spravedlivosti [Notion and Types of Legal Justice]. Rostovshchikov I.V., Rudkovskiy V.A., Gavrilova Yu.A., Abdrashitov V.M., eds. Yuridicheskaya spravedlivost: problemy teorii i praktiki [Legal Justice: Theory and Practice Problems]. Volgograd, Izd-vo VolGU, 2017, pp. 65-83.

9. Voplenko N.N. Svoboda i spravedlivost: zakonomernosti ikh vzaimodeystviya [Freedom and Justice: Interaction Patterns]. Vestnik Volgogradskogo gosudarstvennogo universiteta. Seriya 5, Yurisprudentsiya [Science Journal of Volgograd State University. Jurisprudence], 2012, no. 1 (16), pp. 7-12.

10. Voplenko N.N. Sushchnost, printsipy $i$ funktsii prava [Concept, Principles and Functions of Law]. Volgograd, Izd-vo VolGU, 1998. 56 p.

11. Gelvetsiy K.A. Ob ume [On Mind]. Sochineniya. V 2 t. T. I. [Collected Works. In 2 vols. Vol 1]. Moscow, Mysl Publ., 1973, pp. 326-481.

12. Ivannikov I.A. Problemy gosudarstva i prava Rossii nachala XX veka [The Problems of State and Law in Russia in the Early $20^{\text {th }}$ Century]. Rostov-onDon, Izd-vo Rost. un-ta, 2003. 352 p.

13. Kostareva T.A. Kvalifitsiruyushchie obstoyatelstva $v$ ugolovnom prave (ponyatie, zakonodatelnaya reglamentatsiya, vliyanie na differentsiatsiyu otvetstvennosti) [Qualifying Consequences in the Criminal Law (Notion, Legal
Regulation, Influence on Responsibility Differentiation)]. Yaroslavl, Izd-vo Yarosl. gos. un-ta, 1993. 234 p.

14. Kruglikov L.L., Vasilyevskiy A.V. Differentsiatsiya otvetstvennosti v ugolovnom prave [Differentiation of Responsibility in Criminal Law]. Saint Petersburg, Izd-vo «Yuridicheskiy tsentr Press», 2002. 300 p.

15. Kruglikov L.L., Smirnova L.E. Unifikatsiya v ugolovnom prave [Unification in Criminal Law]. Saint Petersburg, Izd-vo R. Aslanova «Yuridicheskiy tsentr Press», 2008. 312 p.

16. Leist O.E. Yuridicheskaya otvetstvennost [Legal Responsibility]. Marchenko M.N., ed. Obshchaya teoriya gosudarstva $i$ prava. Akademicheskiy kurs: v 2 t. T. 2. Teoriya prava [General Theory of State and Law. Academic Course. In 2 vols. Vol. 2. Theory of Law]. Moscow, Zertsalo Publ., 1998, pp. 592-621.

17. Lesnievski-Kostareva T.A. Differentsiatsiya ugolovnoy otvetstvennosti. Teoriya $i$ zakonodatelnaya praktika [Differentiation of Legal Responsibility. Theory and Legal Practice]. Moscow, NORMA Publ., 2000. 400 p.

18. Livshits R.Z. Teoriya prava [Theory of Law]. Moscow, Bek Publ., 1994. 224 p.

19. Nersesyants V.S. Filosofiya prava [Philosophy of Law]. Moscow, INFRA-M Publ.; NORMA Publ., 1997. 652 p.

20. Filimonov V.D. Norma ugolovnogo prava [Criminal Law Standards]. Saint Petersburg, Izd-vo R. Aslanova «Yuridicheskiy tsentr Press», 2004. 281 p.

21. Tsybulevskaya O.I., Milusheva T.V. Vlast $i$ reformy $v$ Rossii: nravstvenno-pravovoy aspekt [Authority and Reforms in Russia: Moral and Legal Aspects]. Saratov, Povolzhskaya akademiya gosudarstvennoy sluzhby im. P.A. Stolypina, 2003.200 p.

22. Shchepelkov V.F. Ugolovnyy zakon: preodolenie protivorechiy i nepolnoty [Criminal Law: Solving Contradictions and Incompleteness Issues]. Moscow, Yurlitinform Publ., 2003. 416 p.

23. Yavich L.S. Obshchaya teoriya prava [General Theory of Law]. Leningrad, Izd-vo LGU, 1976. $285 \mathrm{p}$.

\section{Information about the Author}

Aleksey P. Rozhnov, Candidate of Juridical Sciences, Associate Professor, Department of Criminal Law, Volgograd State University, Prosp. Universitetsky, 100,400062 Volgograd, Russian Federation, rozhnov@volsu.ru.

\section{Информация об авторе}

Алексей Петрович Рожнов, кандидат юридических наук, доцент кафедры уголовного права, Волгоградский государственный университет, просп. Университетский, 100, 400062 г. Волгоград, Российская Федерация, rozhnov@volsu.ru. 